\title{
Processos da vida, processos da matéria: os diferentes sentidos de natureza entre biólogos e físicos
}

Carolina Lima Alves Belo

Eliane Brígida Morais Falcão

Flavio Silva Faria

Universidade Federal do Rio de Janeiro

\section{Resumo}

Aplicamos a metodologia de análise do Discurso do Sujeito Coletivo (DSC) para comparar as representações sociais relacionadas ao termo natureza em dois grupos de docentes pesquisadores - um de físicos, outro de biólogos - em uma universidade pública brasileira. Foram identificadas cinco classes de discurso coletivo entre os sujeitos investigados, cada uma das quais foi expressa por ambos os grupos. Dois discursos identificados - que denominamos natureza é o natural (DSC1) e natureza é tudo (DSC2) - associam natureza ao não tocado ou originalmente feito pelo homem (DSC1) e a tudo o que compõe o universo (DSC2). Embora de maior adesão em ambos os grupos, o primeiro discurso teve uma adesão mais significativa entre os físicos; o segundo, por sua vez, foi mais frequente entre os biólogos. Dentre as classes de discursos de menor adesão, uma delas foi caracterizada pela dúvida dos sujeitos sobre o significado efetivo de natureza. Os resultados foram discutidos sob duas abordagens: (a) do ponto de vista das relações entre os termos natureza e ambiente no âmbito da educação ambiental, tendo em vista a importância social dos cientistas na formação e na transmissão de conhecimentos relacionados ao assunto; e (b) do ponto de vista das diferenças de fundamentos filosóficos (ontológicos e epistemológicos) entre os dois grupos de cientistas da natureza.

\section{Palavras-chave}

Natureza - Representação social - Físicos - Biólogos. 


\title{
Life processes, matter processes: the different meanings of nature among biologists and physicists
}

Carolina Lima Alves Belo

Eliane Brígida Morais Falcão

Flavio Silva Faria

Universidade Feredal do Rio de Janeiro

\begin{abstract}
We have applied the methodology of Collective Subject Discourse (CSD) analysis to compare the social representations related to the term nature in two groups of teachers-researchers - one of physicists and the other of biologists - from a Brazilian public university. Five classes of collective discourse were identified among the subjects researched, each one of them being expressed by both groups. Two discourses identified - which we labeled nature is the natural (DSC1) and nature is everything (DSC2) - associate nature to that which has not been touched or originally made by men (DSC1), and to everything that comprises the universe (DSC2). Although having more adherents in both groups, the first discourse had a more significant appeal among physicists; the second discourse, in its turn, was more frequent among biologists. Among the less frequent classes of discourse, one of them was characterized by the doubt of the subjects about the effective meaning of nature. The results were discussed under two approaches: (a) from the point of view of the relations between the terms nature and environment within environmental education, considering the social importance of scientists in the creation and transmission of knowledge related to this subject; and (b) from the point of view of the differences in philosophical foundations (ontological and epistemological) between the two groups of scientists of nature.
\end{abstract}

\section{Keywords}

Nature - Social representation - Physicists - Biologists.

Contact:

Eliane Brigida Morais Falcão

elianebrigida@uol.com.br 
A ciência permite ampliar sistematicamente o uso dos recursos naturais, tanto no sentido de garantir a sobrevivência de populações humanas, quanto no de modificar as condições de vida. Essas possibilidades fundam-se no estabelecimento de procedimentos que possibilitam a compreensão dos fenômenos naturais, o que, em grande parte, resume o próprio significado de ciência da natureza. No entanto, tal conhecimento, além de contribuir para a resolução de problemas humanos, pode também gerar outros, como é o caso dos assim chamados problemas ambientais. Faz sentido a frequência com que se vê ser defendida a necessidade de tematizar as relações entre educação, ciência e natureza como um objetivo pedagógico, formalmente proposto nos documentos oficiais que norteiam os processos educativos.

A relação entre o conhecimento científico e a noção de natureza, em particular, tem sido objeto de pesquisas. Uma destas consiste em analisar teoricamente a possível relevância do significado de natureza em controvérsias científicas (HANNIGAN; WYNNE apud CASTRO; LIMA, 2001). Outras visam a levantar dados empíricos e comparativos sobre a representação de nature$z a$ no interior da sociedade moderna (CRESPO; LEITÃO, 1993; REIGADA; TOZONI-REIS, 2004; TAVARES, 2005; FALCÃO; FARIA, 2007).

Levantamentos empíricos têm revelado uma série de componentes heterogêneos nas representações de natureza, sendo alguns deles tentativas de delimitar a abrangência dessa noção. É o caso de visões que concebem o homem como componente da natureza (CRESPO; LEITÃO, 1993) ou que a ele atribuem um status em separado (TAVARES, 2005; FALCÃO; ROQUETE, 2007). Outros referem-se a atitudes em relação à natureza, por exemplo, a atribuição de valor positivo à preservação do ambiente natural. Mas há estudos que apresentam um ponto de vista oposto: a não manifestação de atitudes favoráveis à preservação das condições ambientais (TOZONI-REIS, 2002).

Diferentes explicações poderiam justif1car a persistência de certas visões de natureza
- preocupantes para alguns educadores devido a suas possíveis consequências sociais - tanto em termos de delimitação (separação entre homem e natureza), quanto de atitude (ausência de valores de preservação) (MOSCOVICI, 1985; ROSSI, 2001). Com o presente estudo, gostaríamos de enfatizar que conteúdos culturais de tão longa história, como são os relacionados a visões de natureza, encontram-se enraizados em diferentes meios sociais. Ressaltamos a necessidade de empreender estudos empíricos de modo a mapear as visões de natureza em cada um desses meios; em nossa atividade de pesquisa, temos dado ênfase ao espaço acadêmico onde, para algumas áreas da ciência, estuda-se a natureza.

Assim, a pesquisa aqui relatada concentra seu interesse no ambiente universitário, em que tanto se realizam atividades científıcas de compreensão e aplicação dos processos naturais, quanto se formam professores, cujas atribuições incluem aquela de ensinar novas visões, valores e atitudes em relação aos recursos naturais ou à própria natureza. Ela tem sua origem em resultados que obtivemos em investigação anterior sobre representações de natureza (FALCÃO; FARIA, 2007). Nesse trabalho, percebeu-se que, em um grupo de cientistas (bioquímicos), emergia um reconhecimento de sua própria incapacidade de explicar o que realmente se deveria entender por natureza; certo desamparo intelectual transparecia tão logo os sujeitos começavam a expressar tal incapacidade. Gostaríamos de sugerir que essa reação parece mostrar que, para os próprios cientistas pesquisados, existe aí uma importante lacuna em seus conhecimentos. A identificação desse desamparo, denominado discurso da dúvida, chamou-nos a atenção para a possibilidade de que, no interior de cada um dos poucos - e muito disseminados - tipos de discursos sobre a natureza (tudo é natureza, inclusive o homem; natureza é o que o homem não transformou), possam ocorrer diferenciações relevantes nas atitudes e nos pontos de vista dos membros do meio social que estudamos. 
Dando prosseguimento a esse projeto investigativo, decidimos realizar um estudo comparado das visões de natureza para os cientistas de duas áreas que têm como objetivo investigar os fenômenos da natureza: biologia e física. Com isso, pretendemos (a) ampliar nossa amostragem inicial de cientistas investigados e (b) verificar se os resultados encontrados entre os bioquímicos seriam contingentes a esse grupo enquanto subpopulação de cientistas. Em suma, tratava-se da seguinte questão: haveria alguma relação entre os resultados de pesquisas que mostram oscilações nas tentativas de definir natureza e as especificas visões de docentes pesquisadores que atuam nas áreas especializadas de biologia e física?

A escolha de biólogos e físicos como sujeitos da pesquisa está relacionada ao fato de ambas as áreas pertencerem às ciências da natureza e terem entre suas atividades a produção científica e a formação de professores que atuarão no ensino universitário e básico. Consideramos essa escolha como estratégica, tendo em vista a preocupação dos educadores com a estabilidade e a mudança das concepções de natureza difundidas pela população em geral. Pensamos estar caracterizando um espaço decisivo de produção, tanto quanto de reverberação, de visões de natureza.

Para atingirmos esses objetivos, mantivemos a mesma abordagem teórica e metodológica da pesquisa mencionada (FALCÃo; FARIA, 2007). Foram investigadas as representações sociais (RS) de natureza entre docentes pesquisadores de duas unidades de pesquisa e ensino (física e biologia) de uma universidade pública do Rio de Janeiro. A teoria das RS visa a resgatar a compreensão do mundo a partir das visões elaboradas pelos grupos, indo ao encontro das explicações disseminadas no senso comum (MOSCOVICI, 2003). Seguindo essa linha, Jodelet (2001) define RS como uma forma de conhecimento socialmente elaborada e partilhada, com um objetivo prático, e que contribui para a construção de uma realidade comum a um conjunto social.

\section{A opção pela análise do discurso coletivo}

Os cientistas-docentes por nós estudados eram membros de duas unidades acadêmicas integrantes de uma grande universidade pública. A unidade de física (UF) possuía 120 cientistas-docentes e a unidade de biologia (UB) possuía 78. Doravante, iremos nos referir a eles apenas como docentes. Cerca de 95\% dos docentes de cada unidade eram doutores. A grande maioria de um e de outro grupo dedicava-se tanto a atividades de ensino na graduação (licenciatura e bacharelado) e na pós-graduação (mestrado e doutorado), quanto a projetos de pesquisas científicas.

A metodologia utilizada foi a análise do Discurso do Sujeito Coletivo (DSC) (LEFÈVRE; LEFĖVRE, 2003, 2005), que estabelece procedimentos técnicos de identificação e análise de RS. Lefèvre ressalta o entendimento das representações como compartilhamento de um mesmo imaginário social que pode ser identificado como um produto coletivo analisando-se as respostas individuais. Os dados quantitativos relacionados a aspectos da RS têm por objetivo explorar possíveis elementos que colaborem na interpretação. São utilizadas algumas figuras metodológicas, como expressões-chave (ECh), ideia central (IC) e o discurso do sujeito coletivo (DSC) propriamente dito. As ECh são trechos do que foi falado ou escrito pelos sujeitos e revelam os conteúdos do depoimento. A IC é o que sumariza o sentido básico do grupo de expressões-chave semelhantes ${ }^{1}$. Com cada IC e ECh semelhantes correspondentes, compõe-se um discurso-síntese - o discurso do sujeito coletivo. 0 conjunto dos discursos (DSC) é a representação social do tema ou objeto investigado e mostra ideias, imagens e valores a ele associados; no caso em questão, trata-se da representação de natureza para cada grupo estudado.

1- Segundo a metodologia do DSC, uma representação social pode incluir mais de uma ideia central. No depoimento de um sujeito também se pode encontrar mais de uma ideia central, o que implica dois ou mais discursos diferentes convivendo em um mesmo sujeito. 
Para a obtenção dos dados, realizaram-se entrevistas semiestruturadas. Na UB foram entrevistados 40 docentes em um total de 78, o que representa $51 \%$ da unidade. Na UF foram entrevistados 54 docentes em um total de 100 que estavam presentes na unidade na época das entrevistas ${ }^{2}$, representando $54 \%$ da unidade. Quatro perguntas foram a base das entrevistas: 1) 0 que é natureza para o(a) senhor(a)?; 2) Caneta seria natureza?; 3) O(a) senhor(a) acredita em Deus?; 4) O(a) senhor(a) possui religião, isto é, participa por livre e espontânea vontade de algum culto ou missa? A primeira pergunta visou à expressão de todas as ideias, imagens e valores que cada um teria sobre a natureza. A segunda pergunta pretendeu apurar se objetos produzidos pelo ser humano seriam percebidos como parte ou não da natureza. As duas últimas perguntas só foram formuladas após se ter esgotado todos os aspectos das anteriores, isto é, quando se percebeu que o entrevistado tinha concluído todo seu discurso a respeito do tema natureza. As perguntas sobre religiosidade foram incluídas porque pesquisas anteriores mostraram que crenças religiosas podem influenciar as representações de natureza (MOSCOVICI, 1985; ROSSET, 1989; BROOK; CANTOR, 1998; FALCÃO; FARIA, 2007; FALCÃO; ROQUETTE, 2007; FALCÃO, 2009).
Os dados quantitativos foram organizados em porcentagens, de modo a serem usados como elementos adicionais na interpretação das representações sociais. Os dados qualitativos foram trabalhados pela análise do Discurso do Sujeito Coletivo (DSC). Como apoio à análise desses dados, a Tabela 1 apresenta a distribuição quantitativa das expressões-chave de cada ideia central e de cada grupo.

\section{Definindo natureza: a voz}

\section{dos cientistas}

Seguindo o processo metodológico do DSC, cada grupo foi analisado separadamente. Cinco discursos (DSC) foram construídos a partir das ECh de quatro IC: DSC1 - natureza é o natural (aquilo não criado ou transformado pelo homem); DSC2 - natureza é tudo (tudo aquilo criado, ou não, e transformado, ou não, pelo homem); DSC3 - natureza é Deus (ela é sinônimo de Deus); DSC4 - natureza são valores e sentimentos (a natureza está relacionada a valores como equilíbrio, paz, beleza, pureza, bem estar); DSC-5 - tenho dúvida do que seja natureza (Tabela 1 e Quadro 1). É importante ressaltar que os discursos não foram excludentes, ou seja, uma mesma pessoa pode ter expressado uma ou mais IC em sua fala.

Tabela 1 - Ideias centrais e expressões-chave

\begin{tabular}{|c|c|c|c|c|c|c|}
\hline \multirow{3}{*}{ Ideias centrais } & & & \multicolumn{4}{|c|}{ Professores } \\
\hline & \multicolumn{2}{|c|}{ Total $(n=104)$} & \multicolumn{2}{|c|}{ Biologia $(n=44)$} & \multicolumn{2}{|c|}{ Física $(n=60)$} \\
\hline & $\mathrm{n}$ & $\%$ & $\mathrm{n}$ & $\%$ & $\mathrm{n}$ & $\%$ \\
\hline 1- Natureza é o natural. & 41 & 39 & 27 & 61 & 14 & 23 \\
\hline 2- Natureza é tudo. & 53 & 51 & 13 & 30 & 40 & 67 \\
\hline 3- Natureza é Deus. & 2 & 2 & 0 & 0 & 2 & 3 \\
\hline 4- Natureza são valores e sentimentos. & 1 & 1 & 1 & 2 & 0 & 0 \\
\hline 5- Tenho dúvida do que seja natureza. & 7 & 7 & 3 & 7 & 4 & 7 \\
\hline
\end{tabular}

Fonte: Dados da pesquisa.

2- Parte dos professores de ambas as unidades estavam ou em estudos fora da universidade ou em licença por diversos motivos. 
Quadro 1 - Discursos dos professores-pesquisadores de biologia e física ${ }^{3}$

\begin{tabular}{|c|c|c|}
\hline \multirow{2}{*}{ IC } & \multicolumn{2}{|c|}{ Professores-pesquisadores } \\
\hline & Biologia & Física \\
\hline $\begin{array}{l}\text { DSC1 - } \\
\text { Natureza é o } \\
\text { natural. }\end{array}$ & $\begin{array}{l}\text { Natureza seria aquilo que está lá do lado de fora, } \\
\text { o ambiente natural. o ambiente não é só a relação } \\
\text { entre os seres vivos e meio físico, mas todas as } \\
\text { transformações que esse meio físico sofre. [...] } \\
\text { Natureza é tudo o que existe na biosfera e que não } \\
\text { envolve processos de criação por parte do homem. } \\
\text { Aquela coisa intocada, que não foi feita por ele. } \\
\text { [...] Conjunto de elementos bióticos e abióticos. A } \\
\text { minha concepção de natureza vem mais associada à } \\
\text { concepção de ecossistema. Começa pela concepção } \\
\text { de um ambiente (local) onde você tem um grupo de } \\
\text { seres vivos, que vão interagir entre si e que vão sofrer } \\
\text { influência de fatores físicos e químicos do ambiente. } \\
61 \%\end{array}$ & $\begin{array}{l}\text { É absolutamente tudo que está ao nosso redor, todo ambiente que } \\
\text { foi criado a partir do big bang, que foi sendo desenvolvido ao longo } \\
\text { do tempo e que consigo observar a minha volta. Não foi construído, } \\
\text { modificado ou alterado pelas mãos humanas. Vai desde o macro } \\
\text { até o micro, fenômenos naturais reversíveis que são reproduzidos. } \\
\text { Natureza é todo comportamento conhecido dos eventos naturais, } \\
\text { por exemplo, as marés, a pressão atmosférica, o desenvolvimento } \\
\text { de vida animal e vegetal também é um processo natural. Aquilo que } \\
\text { acontece obedecendo ao que nós sabemos hoje sem interferência } \\
\text { do homem. Natureza é o mundo que a gente vive e o que eu acho } \\
\text { interessante na química, física e biologia é descobrir como esse } \\
\text { mundo funciona. Nós também somos natureza. } \\
23 \%\end{array}$ \\
\hline $\begin{array}{l}\text { DSC2 - } \\
\text { Natureza é } \\
\quad \text { tudo. }\end{array}$ & $\begin{array}{l}\text { Natureza é tudo porque tudo está contido na } \\
\text { natureza. São seres vivos e coisas que interferem em } \\
\text { sua vida, as substâncias que constituem o planeta } \\
\text { e que não tem vida como as rochas e minerais e } \\
\text { diversas formas de energia e que estão conectados } \\
\text { de alguma forma. Natureza é tudo o que nos cerca, } \\
\text { tudo que está no mundo, incluindo todos os seus } \\
\text { aspectos químicos, físicos e biológicos. [...] As coisas } \\
\text { podem ser artificiais, mas na verdade, o artificial é } \\
\text { construído em cima de alguma coisa que veio do } \\
\text { natural, de elementos que fazem parte da natureza. } \\
30 \%\end{array}$ & $\begin{array}{l}\text { Natureza é o conjunto de fenômenos que acontecem a nossa volta } \\
\text { e que são regidos por leis fundamentais. Qualquer coisa que nos } \\
\text { cerca faz parte da natureza [...]. Não é aquela sensação pura de ter a } \\
\text { natureza como aquela coisa intocável. A natureza é tudo que inclusive } \\
\text { faz parte do contato com o homem e o homem também estaria } \\
\text { incluído, ou seja, nós mesmos. A natureza seria um conjunto de entes } \\
\text { fundamentais (partículas) e suas interações. Vai desde o sub-nuclear até } \\
\text { a cosmológica. Dentro desse artefato, existem átomos, partículas que se } \\
\text { comportam segundo as leis da natureza.[...]. Tudo que posso perceber } \\
\text { com meus sentidos, inclusive coisas que não vemos e não podemos } \\
\text { detectá-las pelas nossas limitações de sentidos e pelos instrumentos } \\
\text { que temos, o que a gente vê e o que a gente não vê, mas sabe que estáa } \\
\text { ali [...] Tudo o que existe, inclusive o que não conseguimos observar, } \\
\text { processos físicos, químicos, biológicos, econômicos, sociais. } \\
67 \%\end{array}$ \\
\hline $\begin{array}{l}\text { DSC3 - } \\
\text { Natureza é } \\
\text { Deus. }\end{array}$ & Discurso não expresso. & $\begin{array}{l}\text { Natureza e Deus se confundem. } 0 \text { que eu chamo de natureza, poderia } \\
\text { chamar de Deus. }\end{array}$ \\
\hline $\begin{array}{l}\text { DSC4 - } \\
\text { Natureza } \\
\text { são valores e } \\
\text { sentimentos. }\end{array}$ & $\begin{array}{l}\text { Natureza tem vários significados pessoais, como o } \\
\text { lugar de descansar do mundo humano. } \\
2 \%\end{array}$ & Discurso não expresso. \\
\hline $\begin{array}{l}\text { DSC } 5 \text { - Tenho } \\
\text { dúvidas do } \\
\text { que seja } \\
\text { natureza. }\end{array}$ & $\begin{array}{l}\text { Antes de falar propriamente sobre o que eu acho } \\
\text { que seja natureza, talvez seja importante mencionar } \\
\text { que esse conceito não vinha sendo uma coisa sobre } \\
\text { a qual eu me dedicasse a pensar. Nunca pensei a } \\
\text { respeito. É algo que passa despercebido. } \\
7 \%\end{array}$ & $\begin{array}{l}\text { É uma pergunta difícil. Nunca pensei nisso, apesar de ser um } \\
\text { estudioso da mesma. É algo que já é intrínseco, não se para pensar } \\
\text { a respeito. } \\
7 \%\end{array}$ \\
\hline
\end{tabular}

Fonte: Dados da pesquisa.

Dois discursos apresentaram maior adesão por parte dos dois grupos: DSC1 e DSC2. No entanto, houve diferença entre os dois grupos de cientistas na adesão a eles: conforme exposto na Tabela 1, os biólogos aderiram mais ao DSC1 e

3- Para fins de adequação ao espaço disponível ao artigo sem prejuízo do entendimento dos discursos, foram omitidas expressões-chaves que eram muito semelhantes. os físicos aderiram mais ao DSC2. Os dois grupos também diferiram quanto às imagens e ideias que usaram na constituição de seus discursos, pois enfatizaram processos e entidades relacionadas aos seus interesses e às suas vivências profissionais. A constante referência a seres vivos e processos da vida, por parte dos biólogos, foi mais especificamente marcada por um conteúdo 
ecológico e proveniente das ciências ambientais, como ecossistema, meio ambiente, biosfera ou relações entre comunidades bióticas e componentes abióticos. A propósito desse último elemento discursivo (elementos abióticos), deve-se observar que a predominância do vivo não impediu a enumeração de entidades não vivas dentre os componentes de natureza. Correlativamente, os físicos recorreram a um variado elenco de conteúdos com que estão familiarizados, principalmente partículas e átomos, mas também energia, big bang etc. Com uma ênfase exatamente inversa à dos biólogos, os seres vivos também são mencionados, porém com menor frequência.

Em relação ao discurso DSC4, expresso somente entre os biólogos, percebe-se a presença do que poderíamos chamar de associações românticas de harmonia, prazer e beleza com a natureza. No Romantismo, havia a valorização das emoções, e a fuga da realidade e o escapismo eram características marcantes; por isso, ao referirmo-nos a associações românticas de natureza, queremos dizer que esta se apresentava como um refúgio a tal ser humano que desprezava a razão imposta pelo Iluminismo e valorizava as emoções. Devido a essa característica, a natureza era frequentemente associada a emoções de prazer e beleza (VON ENGELHARDT, 1997; BONNET, 2003; BRAGA; GUERRA; REIS, 2005).

0 discurso DSC3 esteve presente somente entre os professores da UF. É provável que tal discurso esteja relacionado a tendências subjetivas de expressão religiosa no mundo moderno (SEGATO, 1999; GEERTZ, 1989), sendo que aqueles que o expressaram não estão vinculados a religiões, mas disseram acreditar em Deus. Não está clara a ideia de Deus que tal discurso exprime, mas pode-se dizer que há pouca chance de que ele revele algum tipo de tendência panteísta.
Isso porque o numero de professores dessa unidade que admitiram crer em Deus foi de catorze (27\% do total), aos quais poderíamos acrescentar os onze (22\%) que admitiram ter dúvidas (ver Tabela 2); já o discurso natureza é Deus foi expresso apenas por dois (4\%) dos entrevistados. As respostas às perguntas sobre Deus e religião mostram-nos mais dois aspectos dignos de nota entre os docentes investigados. 0 primeiro é que, em ambos os grupos, a crença em Deus não parece envolver qualquer compromisso institucional, talvez nem mesmo doutrinário, pois os que participam de cultos e/ou filiam-se a uma religião são minoritários: $2 \%$ dentre os físicos e $5 \%$ dentre os biólogos, ainda que alguns não tenham respondido. Em segundo lugar, a crença em Deus é mais pronunciada entre biólogos do que entre físicos. Aqui, chamamos a atenção para a inversão das proporções entre os dois grupos (se não incluirmos os que têm dúvidas em nenhuma das duas categorias) na resposta à pergunta "O(a) senhor(a) acredita em Deus?". Conforme se vê na Tabela 2, as proporções obtidas foram de $47 \%$ sim contra 34\% não entre os biólogos e $27 \%$ sim contra 51\% não entre os físicos.

Os discursos natureza são valores e sentimentos e natureza é Deus, de fraca expressão em ambos os grupos, remetem à consciência dos limites da ciência e mereceriam uma investigação específica. Tem crescido entre cientistas, e mesmo na sociedade em geral, a consciência de que a ciência não só não resolve todos os problemas humanos como também está envolvida com decisões de dimensões subjetivas, ou seja, que envolvem valores e visões de mundo. Entretanto, não se pode dizer que a formação científica, e mesmo o cotidiano da vida acadêmica, ofereça espaços regulares de reflexão sobre tais aspectos (CASTRO; LIMA, 2001; TOZONI-REIS, 2002; BONNET, 2003).

Tabela 2 - Crença em Deus pelos professores pesquisadores da UB da UF

\begin{tabular}{|c|c|c|c|c|c|c|}
\hline \multirow{3}{*}{$\begin{array}{l}\text { Crença em Deus } \\
\text { (com e sem religião)* }\end{array}$} & \multirow{2}{*}{\multicolumn{2}{|c|}{ Total $(n=89)$}} & \multicolumn{4}{|c|}{ Professores } \\
\hline & & & \multicolumn{2}{|c|}{ Biologia $(n=38)$} & \multicolumn{2}{|c|}{ Física $(n=51)$} \\
\hline & $\mathrm{n}$ & $\%$ & $\mathrm{n}$ & $\%$ & $\mathrm{n}$ & $\%$ \\
\hline Sim & 32 & 36 & 18 & 47 & 14 & 27 \\
\hline Não & 39 & 44 & 13 & 34 & 26 & 51 \\
\hline Tem dúvidas & 18 & 20 & 7 & 18 & 11 & 22 \\
\hline
\end{tabular}


Em superposição aos enunciados classificados como natureza é o natural e natureza é tudo podem-se identificar alguns outros componentes discursivos. Não os consideramos como classes de DSC porque apareceram mais como qualificações dos discursos (DSC1 e DSC2). Embora de caráter subordinado, revelam diferenças significativas entre os dois grupos de cientistas: certas notas marcantes do referente de natureza ou o modo de ser de coisas e objetos. Com relação aos físicos, observa-se que, tanto entre os que identificaram natureza em oposição ao artificial, quanto entre aqueles que se referiram à natureza como tudo, foi bastante frequente a referência aberta ou velada a leis da natureza. Um exemplo de referência velada é a seguinte menção: "aquilo que acontece obedecendo ao que nós sabemos hoje sem interferência do homem" (DSC1, físicos). Outro exemplo, menos nítido, pode ser identificado em: "fenômenos naturais reversíveis que são reproduzidos" (DSC1, físicos). Foram encontradas várias referências desse tipo, tanto entre os físicos que expressaram DSC1 (natureza é o natural), quanto entre os que expressaram DSC2 (natureza é tudo). Também se identificou, ainda entre os físicos, a preocupação em caracterizar a natureza em termos de composição. Aí encontramos ora uma referência a átomos e partículas subatômicas, ora uma referência generalizada à matéria. Recorrendo à história da filosofia natural (CASINI, 1987), poderíamos dizer que esses enunciados buscam descrever a nature$z a$ em termos de causas materiais aristotélicas: aquilo de que as coisas são feitas. Contudo, diferentemente do que propunha o antigo filósofo grego, essa matéria parece referir-se a um tipo de componente global do universo identificado à natureza (pois, para esses sujeitos, natureza é tudo). Ainda entre os físicos, os objetos e as coisas naturais - quer sejam tudo (DSC2) ou apenas o que não foi tocado pelo homem (DSC1), perfazem um conjunto entre cujos elementos existiriam interações. A noção de conjunto, mesmo se qualificada pela existência de interações, sugere fortemente uma composição por agregação: interação é ação recíproca entre coisas independentes. Conjunto ou coleção foi usado mais frequentemente do que interação. Cabe destacar aqueles casos em que o termo conjunto não foi utilizado, pois os sujeitos em questão recorreram a metáforas que exprimem algum sentido de integração: a natureza como artefato (DSC2, físicos) e como máquina do universo (DSC2, físicos).

Por fim, é preciso notar como os enunciados dos físicos fazem-se acompanhar por referências epistemológicas que vão desde a caracterização da natureza como objeto de conhecimento, até o problema da limitação dos sentidos e o recurso a instrumentos de observação e mensuração. Considere-se o seguinte exemplo do DSC1, que consiste em um enunciado indireto: "eu acho interessante... é descobrir como funciona". Grosso modo, alguns traem uma influência empirista, identificando o todo da natureza ao observável, com ou sem aparelhos, e outros mencionam o que está além da observação, com ou sem referência a aparelhos. Exemplos desse segundo caso são expressões do tipo "o que a gente vê e o que a gente não vê, mas sabe que está ali"; ou "tudo o que existe, inclusive o que não conseguimos observar" (DSC2, físicos).

No grupo dos biólogos, em contraste com o dos físicos, não há qualquer referência às leis da natureza. Por outro lado, os enunciados que, entre os físicos, dizem respeito ao modo de composição da natureza, expresso por termos como conjunto e interação, são muito mais ricos de variação e, possivelmente, de significados entre os biólogos. 0 termo interação foi usado principalmente entre os sujeitos que se exprimiram por meio do DSC1 (natureza é o natural), quase tão frequente quanto o uso do termo relação. Esse termo exprime um vínculo de integração bem mais evidente do que o termo interação. Se considerarmos as referências ao conceito de ecossistema como exemplo do que se entende por natureza, bem como o significado de conexão, poderíamos pensar que a ideia de sistema integrado - ou talvez de sistemas 
integrados, no plural - mostra-se mais explicitamente entre os biólogos, sendo inclusive mais frequente do que a simples interação.

Diferentemente dos físicos, não há nenhuma classe de entidade que seja explicitamente apresentada como fundamental, quer se trate de algum tipo de partícula, quer se trate de entidades particuladas em geral; nem mesmo o termo genérico matéria foi assim mencionado. E isso ocorreu apesar da ocasional referência aos componentes abióticos dos ecossistemas ou da referência genérica a fatores físicos e químicos. Salta aos olhos a quase total falta de referências epistemológicas entre os biólogos. Apenas um dos sujeitos entrevistados caracterizou a natureza explicitamente como objeto de conhecimento: "tudo o que é fisicamente observado ou medido pelos seres humanos".

Um discurso com expressões de perplexidade foi manifestado por ambos os grupos, a partir do momento em que tentavam articular uma resposta: "Antes de falar propriamente sobre o que eu acho que seja natureza, talvez seja importante mencionar que esse conceito não vinha sendo uma coisa sobre a qual eu me dedicasse a pensar" (biólogo); "Nunca pensei a respeito" (biólogo); "Nunca pensei nisso" (físico); "É uma pergunta difícil" (físico). A esse reconhecimento do caráter não óbvio do termo a ser explicado (natureza) - o que já observamos em outro estudo (FALCÃO; FARIA, 2007) - denominamos discurso da dúvida. Trata-se de uma posição minoritária, mas cuja presença sugere que estamos diante de uma fragilidade intelectual.

\section{Discursos diferenciados, modos de ser dos cientistas}

A análise comparativa entre as RS de $n a-$ tureza expostas no Quadro 1 e os dados sobre religiosidade expostos na Tabela 2 permitiu-nos identificar semelhanças e diferenças entre os grupos investigados. As semelhanças dizem respeito ao fato de que ambos os grupos pertencem ao campo da ciência, o que se manifestou em três discursos apresentados no Quadro 1.
Os discursos natureza é Deus (DSC3) e natureza são valores e sentimentos (DSC4) tiveram pouquíssima adesão. Por outro lado, o discurso tenho dúvidas do que seja natureza (DSC5), conquanto não seja majoritário, atingiu um nível de adesão apreciável. Devemos notar que os discursos DSC3 e DSC4, em nossas pesquisas, têm alcançado índices de adesão mais elevados do que em outros grupos sociais estudados. Além disso, até agora, só nos deparamos com o discurso da dúvida (DSC5) em pesquisas com cientistas. Devemos portanto enfatizar a semelhança aí revelada entre físicos e biólogos, bem como a semelhança destes com nossos estudos anteriores sobre cientistas (FALCÃO; FARIA 2007).

Quanto às diferenças observadas, podemos remetê-las ao campo especializado a que um e outro grupo se dedicam: processos da vida, para os biólogos; processos de transformações físico-químicas de átomos e partículas, para os físicos. Para os biólogos, natureza é o natural, sobretudo aquilo que não foi criado pelo homem - os processos da vida; para os físicos, natureza é tudo aquilo composto de partículas. Constatam-se, pela representação social produzida por esses grupos, os indícios claros da realidade profissional em que estão inseridos, ou seja, os discursos ali produzidos são parte de uma cultura ${ }^{4}$ de um grupo social - no caso, dois grupos acadêmicos de duas diferentes áreas da ciência. Debates recentes sobre metodologia e filosofia da ciência natural podem iluminar detalhes importantes que os diferenciam.

Em primeiro lugar, há que destacar a frequência de ocorrência das ideias mais abrangentes de natureza (DSC1 - natureza é o natural; DSC2 - natureza é tudo) em cada um dos dois grupos. A importância relativa de DSC1 entre os biólogos - cerca de metade das expressões individuais -, em contraste com aproximadamente um quarto entre os físicos, provavelmente reflete a forte ligação da atividade daqueles cientistas com os problemas ambientais. Os padrões de

4 - Para Geertz (1989), cultura é um sistema de significados expressos em símbolos. Ele referiu-se a esse sistema como teia de sentidos. Os grupos sociais produzem e, ao mesmo tempo, incorporam cultura. 
ocorrência de espécies animais, vegetais, de microorganismos etc., bem como o grau de diversidade biológica em diferentes ambientes são temas que trazem para primeiro plano a ideia de natureza como algo sobre o qual interferimos. Isso porque a vida, se entendida em termos de suas manifestações particulares - espécies -, tende a ser vista como um aspecto particularmente frágil do universo: a eliminação de qualquer uma dessas unidades é irreversível. Embora a extinção seja parte do arsenal de conceitos referentes ao natural, ela também é fortemente associada às possíveis consequências dos poderosos meios de ação material atualmente usados pelos humanos. Devemos considerar que esse viés do pensamento dos biólogos, no que ele tem de especificidade profissional, poderia ter uma fonte adicional, menos tingida por preocupações sociopolíticas ou pragmáticas. Ocorre que as atuais configurações biogeográficas são resultantes de processos bio-históricos de longuíssima duração, ao passo que os efeitos mais drásticos da ação humana remontam a, no máximo, cem anos, se tanto. Sendo assim, não raramente os cientistas que visam a resultados e elaborações teóricas válidas para uma escala de tempo ampla veem-se obrigados a estudar territórios ou regiões onde os efeitos da revolução industrial (ou das revoluções industriais) e da expansão populacional humana sejam os menores possíveis. É razoável admitir que a busca do intocado resulta de uma necessidade metodológica, inerente ao próprio estudo da vida.

Essa mesma explicação - o viés profissional na definição de natureza - é compatível com o resultado diferente observado entre os físicos. As entidades teóricas e os exemplares empíricos por eles considerados - partículas, átomos, campos, forças - aparecem como não suscetíveis de desintegração definitiva ou extinção; além disso, a abrangência no espaço/ tempo desses objetos é muito mais vasta: praticamente todo o universo está efetivamente vinculado ao esforço teórico, ou mesmo de observação e experimentação dos físicos (basta pensar na astrofísica e na cosmologia). É certo que os esforços teóricos dos biólogos visam a objetos independentes das condições particulares de existência desta ou daquela comunidade biótica, ou mesmo desta ou daquela espécie de organismo. E também é certo que a astrobiologia preocupa-se com a possibilidade da detecção de vida em outros corpos celestes. Porém, de maneira geral, a biologia continua a ser, esmagadoramente, uma ciência cujo objeto restringe-se ao nosso planeta; ou talvez a um espaço ainda mais restrito e extremamente mutável: uma estreita faixa planetária denominada biosfera.

Aqui se faz necessária uma qualificação dos resultados e das conclusões que deles podem ser derivadas. Grande parte das atividades teóricas e experimentais ou mesmo das aplicações práticas sob a rubrica biologia ou ciências da vida inclui disciplinas cujos objetos (a) abrangem a vida em geral, em seus mecanismos básicos, e não a biodiversidade ou a estrutura de comunidades biológicas, e (b) não exigem uma permanente ida ao mundo lá fora, para além do laboratório. É o que vemos em uma infınidade de linhas de pesquisa em bioquímica, biologia celular, imunologia, fisiologia e outros campos. Sendo assim, é relevante mencionar que a instituição onde trabalham os biólogos apresenta uma forte ênfase em assuntos ambientais, ecologia, biodiversidade, evolução e sistemática. Desse modo, não deveríamos considerar nossa fonte como uma amostragem dos biólogos em geral, porém mais propriamente como de um subconjunto deles.

0 fator especificidade profissional chega a ser forte o suficiente para determinar os próprios substantivos e as imagens mais frequentemente usadas pelos membros dos dois grupos de cientistas. Basta constatar a menção a partículas, átomos e forças, em contraposição à menção a ecossistemas. Contudo, de acordo com os resultados, não poderíamos considerar como absoluta a influência desse fator. Nem os biólogos resumem-se às referências ao vivo ou a conceitos ecológicos, nem os físicos deixam de incluir seres vivos em suas concepções do natural. Mais importante ainda é o fato de que as 
suas concepções de natureza mais abrangentes podem ser consideradas como muito relevantes para os dois grupos. Conforme já exposto em trabalho anterior (FALCÃO; FARIA, 2007), a opinião de outros grupos sociais, que não cientistas, também é marcada pela justaposição de natureza é o natural e natureza é tudo. Temos razão, então, para sugerir que a influência do empenho profissional específico dos cientistas se superpõe a uma influência de ocorrência mais generalizada, em termos sociais.

Outro aspecto diz respeito às atitudes em relação ao meio ambiente, as quais são objeto de preocupação de professores interessados em educação ambiental. Os depoimentos de ambos os grupos de cientistas parecem ter um conteúdo neutro. A simples manifestação da ideia de que natureza é o não tocado pelo homem pode muito bem ser entendida como coerente com uma atitude de preservação bastante justificável, mesmo que ligada a interesses profissionais (no caso dos biólogos, principalmente). Mas a ideia de reserva (ecológica e ambiental) também se estende à preservação de recursos exigidos cotidianamente pelo bem-estar das comunidades humanas. Esse mesmo discurso pode desenvolver-se no sentido de estabelecer uma separação entre homem (ou nós) e natureza.

0 discurso segundo o qual natureza é tudo também se prestaria a desenvolvimentos em direções opostas. Ele pode ser entendido como uma decidida quebra da barreira entre homem e natureza, favorecendo uma atitude mais prudente em relação às nossas realizações técnicas. Por outro lado, tal discurso pode trivializar as consequências da expansão numérica da humanidade acompanhada do uso intenso de métodos de produção cada vez mais poderosos em suas capacidades de transformar as características físicas e bióticas do meio ambiente. Afınal de contas, se natureza é tudo, então tudo o que fazemos é natureza $a^{5}$.

5- Não é difícil encontrar biólogos que, diante dos possíveis riscos decorrentes da utilização de organismos geneticamente modificados, replicam que essas modificações são as mesmas que os organismos sempre sofreram durante a evolução.
Os dois grupos de cientistas também diferiram em seus enunciados quanto a certas notas mais específicas expressas em seus discursos - a menção a leis da natureza, observação e instrumentos, bem como a frequência relativa de termos como interação ou relação. Não é difícil perceber que tais componentes discursivas revelam diferenças quanto à expressão explícita de princípios filosóficos. Podemos sistematizar essas referências recorrendo a uma obra recente de introdução à metafísica. As páginas iniciais desse livro detém-se em três pressupostos sem os quais a física (e, presumidamente, as chamadas ciências da natureza, em geral) não poderia sequer começar: (1) existe uma realidade física exterior aos nossos estados mentais; (2) as interações daquilo que constitui essa realidade conformam-se a certas leis gerais; e (3) somos capazes de apreender as leis físicas e obter evidências favorecendo ou desfavorecendo a proposição de certas leis. 0 autor enfatiza que, desses pressupostos, os dois primeiros são metafísicos (ontológicos), enquanto o terceiro é epistemológico (JUBIEN, 2007).

Os três pressupostos podem ser encontrados em discursos expressos pelos físicos. É possível identificar um claro contraste em relação aos biólogos. Entre estes, poderíamos no máximo apontar que a oposição entre homem e natureza - típica do DSC1 - seria uma expressão da oposição entre sujeito e objeto do conhecimento. Contudo, essa oposição praticamente nunca se faz acompanhar de termos característicos da teoria do conhecimento, como percepção e observação. A identificação desses enunciados epistemológicos e ontológicos no discurso dos físicos (raramente mencionados entre os biólogos) é relevante porque a noção sobre a qual eles foram interrogados - natureza - é, ela própria, anterior à ciência propriamente dita. Trata-se mais de um pressuposto do que de um dos conceitos componentes da estrutura teórica (da física ou biologia). 0 tipo de discurso manifestado pelos físicos já seria de se esperar, se levarmos em conta os livros-texto de física, em que estão detidamente examinados assuntos 
como instrumentos de observação, mensuração etc. (TIPLER, 1991; GIANCOLI, 2008). A forma típica de exposição de um bom número de teorias físicas dá-se em torno do enunciado de leis - como as leis de Newton, a lei de Boyle e diversas leis de conservação.

É possível fazer dois comentários a respeito dos biólogos. 0 primeiro diz respeito aos objetos e à própria estrutura das ciências da vida: talvez esse campo do saber tenha como assunto objetos cujas possibilidades de variação são bem mais ricas do que nos objetos próprios à física. Essas possibilidades de variação tornariam, em geral, proibitivas quaisquer possibilidades de constituição de modelos muito simples. Sendo assim, as inúmeras particularidades das variações do objeto de estudo levariam necessariamente a uma atitude mais empirista e menos teorizante por parte dos biólogos. Isso porque não haveria muitas grandezas de alcance universal a serem seguidamente medidas, de modo a conseguir um valor tão exato quanto possível; da mesma forma (ou, talvez, exatamente por isso), dificilmente o objeto biológico deixaria defınir-se por enunciados como os das leis físicas. Desse ponto de vista, a diferença filosófica por nós observada entre físicos e biólogos não deveria suscitar maiores problemas.

Porém, é possível desenvolver comentários e considerações de outra ordem. Mesmo que chegássemos a um consenso a respeito das diferenças fundamentais entre os objetos da física e da biologia, ainda assim poderíamos supor que as ciências da vida repousam sobre certos pressupostos ontológicos e epistemológicos. Poderíamos perguntar se o discurso dos biólogos, com pouquíssimas referências filosóficas, não revela uma deficiência que deveria ser mais bem cuidada. $\mathrm{Ou}$ seja, trata-se de saber se seria ou não desejável introduzir mudanças em currículos de formação científica, particularmente no caso das ciências da vida, de modo a expor os alunos a discussões histórico-filosóficas. Essa é uma pergunta já levantada em artigo anterior de nosso grupo de pesquisa (FALCÃo; FARIA, 2007). Naquela ocasião, chamamos a atenção para a existência de um discurso da dúvida entre os bioquímicos: vários deles admitiram que se sentiam confusos ao tentarem enunciar o que é natureza, fato que nos levou à discussão sobre a abordagem de temas filosóficos na formação científica.

Mediante a comparação entre biólogos e físicos, o problema da formação filosófica dos cientistas volta a destacar-se, mas sob outro enfoque. A insistência do discurso dos físicos sobre leis da natureza (referência que, em leve divergência para com Jubien, poderíamos conceber como remetendo tanto ao domínio epistemológico quanto ao ontológico) reflete o prestígio ainda forte de modelos nomológico-dedutivos da racionalidade científica. Tais modelos baseiam-se em uma restrição do enunciado científico a uma dedução lógica, ou proposicional, dependente de uma lei. Assim, o pensamento avançaria de uma lei (ou mais de uma), mais algumas condições materiais, para uma dedução lógica de consequências. Além disso, a lei é concebida como uma regularidade universal.

No entanto, a literatura em filosofia da ciência das últimas três décadas viu ganhar força um modo bastante diferente de explicar o andamento do pensamento científico. Uma das razões para buscar outro caminho é justamente dar conta dos problemas apresentados pelo estatuto ontológico das leis, entendidas como regularidades universais. As leis são leis do quê? Se a regularidade dos fenômenos, em geral, depende do isolamento do laboratório, então o que rege os fenômenos fora dessas condições? E, nesse caso, poderíamos realmente dizer que conhecemos alguma coisa? Qualquer regularidade pode ser equiparada a uma causa, no sentido de explicação científica? (HARRÉ; MADDEN, 1975; BHASKAR, 1977).

É a fim de responder a esses questionamentos que se vem propondo que a explicação científıca efetivamente usada pelos cientistas baseia-se na caracterização de mecanismos ou estruturas e que a lei deve ser encarada como um enunciado do modo esperado de ação desses mecanismos. Há que ressaltar que o mecanismo costuma ser representado como um 
dispositivo complexo, com partes articuladas no espaço e dotado de certa duração no tempo; que, em determinados domínios do real - sejam estes considerados como naturais ou sociais -, cada mecanismo especificamente diferenciado aparece sob certa quantidade de exemplares. 0 termo mecanismo não deve ser entendido no sentido seiscentista, ou setecentista, de dispositivos dotados de interações por percussão, pressão, contato. Estes também devem ser considerados como mecanismos, no sentido aqui discutido, mas o termo filosófico atualmente proposto refere-se a estruturações cujas partes interagem segundo muitos outros modos de ação (atração magnética, em certos sistemas físicos; influências pessoais, em sistemas sociais) (GLENNAN, 2002).

É interessante notar que, nos trabalhos mais recentes sobre esse assunto, chamou-se a atenção para o fato de que a escassez de leis na teorização biológica é compensada por uma permanente referência a mecanismos. As razões disso estariam, em grande parte, na complexidade trazida aos objetos de pesquisa dos biólogos pelo modo como variam as estruturas biológicas (BECHTEL; ABRAHAMSEN, 2005). Muito importante é a sugestão de que, ainda no domínio biológico, mesmo onde se enunciam leis, o desenrolar do pensamento científico parece estar mais preso aos mecanismos. Assim é que as famosas leis de Mendel apenas descrevem consequências regulares - sob certas condições - de algo que é muito mais básico: a mecânica cromossômica, uma estrutura (GLENNAN, 2010). Por outro lado, os filósofos da ciência aqui mencionados de forma alguma consideram esse recurso a mecanismos como uma especificidade das ciências da vida, mas tentam mostrar como as explicações em física e em ciências sociais têm-no como implícito.

É preciso voltar aos comentários já apresentados sobre o uso de termos como relação, complexidade e ecossistema em referência a natureza, por parte dos biólogos investigados. Essa ênfase no complexo, que não possui referência a leis ou regularidades, mas que, no entanto, é objeto de estudo por parte dos cientistas, poderia significar não um fechamento definitivo para a análise filosófica, mas o caminho para o desenvolvimento de um conceito de natureza plenamente adequado ao pensamento desses cientistas. Bastaria, para isso, chamar a atenção deles para a ideia de natureza como um sistema de estruturas interconectadas e/ou integradas (BECHTEL; ABRAHAMSEN, 2005).

\section{Considerações finais}

Se, por um lado, os resultados relacionam-se com as práticas de trabalho em física e biologia, por outro, revelam limitações nas suas representações de natureza. São parcialidades de visões produzidas à luz de práticas do cotidiano profissional de cada grupo, reveladas como representações sociais no sentido tratado por Moscovici: as características dos grupos e do objeto nelas se manifestaram. Expusemos uma diferenciação entre os dois grupos, com base em temas religiosos; tal conclusão justifica-se ao levarmos em conta os dados sobre a crença em Deus - mais elevada entre biólogos do que físicos. Esse tema poderá ser aprofundado em uma nova pesquisa, em que poderíamos interrogar físicos e biólogos a respeito de seus conceitos de vida e matéria e também sobre a visão pessoal que têm a respeito de temas de fundo cosmogônicos, como origem da vida e do universo.

Certamente devem ser levadas em conta as preocupações daqueles que constatariam, nas representações de natureza de ambos os grupos, um condicionamento do que já se apontou como limitações para uma visão integrada de natureza. Essa expressão traduz uma postura crítica em relação a visões que mantêm uma separação entre homem e natureza, ou um isolamento entre componentes do mundo natural.

Mais particularmente, devemos enfatizar que discursos sobre separação ou integração entre homem e natureza estão habitualmente incorporados à fundamentação teórica de propostas sobre os rumos e objetivos da educação ambiental. Tal incorporação já era perceptível 
no inicio dos anos 1990 e faz-se ainda presente nos estudos mais recentes, de acordo com a literatura apresentada neste trabalho.

Contudo, conforme insistimos em nossa discussão, essas preocupações devem ser matizadas por diversas considerações. Uma delas consiste na constatação de que não devemos estabelecer uma ligação direta entre qualquer uma das concepções de natureza mais frequentes - natureza é tudo e natureza é o intocado - e atitudes presumidamente mais positivas ou negativas em relação aos ideais de preservação e de condições de existência saudáveis para a humanidade. Exatamente por isso - e esta é uma segunda consideração importante -, também não seria apropriado atribuir atitudes diferenciadas de responsabilidade social aos dois grupos de cientistas. A predominância de um ou outro daqueles dois discursos mais frequentes pode ser explicada pelo direcionamento dos membros de cada um dos grupos para determinados $o b$ jetos naturais: a predominância de uma ou outra atitude é, em grande parte, consequência de interesses intelectuais constitutivos da própria disciplina científica. A ciência implica atividade analítica de seus objetos e, embora o enfoque em aspectos ou partes resulte em avanços na compreensão dos fenômenos, ele traz, por outro lado, a possibilidade de uma visão fragmentada do mundo e do conhecimento. Esse é um risco inerente a praticamente todas as atividades que caracterizam o mundo atual. Dar conta dele no âmbito dos cientistas por nós investigados depende de complexas intervenções institucionais no seio da organização acadêmica, tanto quanto no quadro de ideias correntes. Quanto a essa segunda dimensão, a das ideias, podemos concluir que os discursos sobre natureza revelaram uma considerável diferença entre biólogos e físicos no plano dos pressupostos filosóficos que enquadram suas atividades, e isso inclui uma maior propensão dos físicos a explicitar esses pressupostos, em seus discursos sobre natureza. Por um lado, essa diferença poderia impor dificuldades a futuras iniciativas de integração entre diferentes áreas do conhecimento; por outro lado, a diversidade de pontos de vista poderá revelar-se uma fonte de opções alternativas no desenvolvimento do pensamento científico.

É possível concluir sugerindo que, no âmbito da educação ambiental, a articulação entre os diversos saberes formulados por cientistas da natureza de diferentes áreas deverá ser uma preocupação tão premente quanto a de identificar características sociais do pensamento desses profissionais acadêmicos. 


\section{Referências}

ABRANTES, Paulo Cesar C. Imagens de natureza, imagens de ciência. Campinas: Papirus, 1998.

BECHTEL, William; ABRAHAMSEN, Adele. Explanation: a mechanistic approach. Studies in the History and Philosophy of the Biological and Biomedical Sciences, n. 36, p. 421-441, 2005.

BHASKAR, Roy. A realist theory of science. London: Verso, 1977.

BONNET, Michael Notions of nature. Journal of Philosophy of Education, v. 37, n. 4, p. 577-592, 2003.

BRAGA, Marco; GUERRA, Andreia; REIS, José Claudio. Breve história da ciência moderna, volume 3: Das luzes ao sonho do doutor Frankenstein (século XVIII). Rio de Janeiro: Jorge Zahar Editor, 2005.

BROOK, John; CANTOR, Geoffrey. Reconstructing nature. Oxford: Oxford University Press, 1998.

CASINI, Paolo. As filosofias da natureza. Lisboa: Editorial Presença, 1987.

CASTRO, Paula; LIMA, Maria Luísa. Old and new ideas about the environment and science: an exploratory study. Environment and Behavior, n. 33, p. 400-423, 2001.

CRESPO, Samyra; LEITÃO, Pedro. 0 que o brasileiro pensa da ecologia. Rio de Janeiro: MAST/CNPQ/CETEM/AGÊNCIA O ESTADO/ ISER, 1993.

FALCÃO, Eliane B. Morais. The conflict between science and religion: a discussion on the possibilities for settlement. Cultural Studies of Science Education, n. 5, p. 47-54, 2009.

FALCAO, Eliane B. Morais; FARIA, Flavio Silva. Os sentidos da natureza na formação e na prática científica. Educação e Pesquisa, São Paulo, n. 33, n. 2, p. 336-349, 2007.

FALCAO, Eliane B. Morais; ROQUETTE, Gustavo Sulzer. As representações de natureza e sua importância para a educação ambiental: uma pesquisa em quatro escolas. Ensaio: Pesquisa em Educação em Ciências, Belo Horizonte, v. 9, n. 1, 2007.

GEERTZ, Clifford. A interpretação das culturas. Rio de Janeiro: Guanabara Koogan, 1989.

GIANCOLI, Douglas C. Physics for scientists and engineers. Prentice Hall, 2008.

GLENNAN, Stuart. Rethinking mechanistic explanations. Philosophy of Science, n. 69, p. S342-S353, 2002. 362-381, 2010.

Mechanisms, causes, ande the layered model of the world. Philosophy and Phenomenological Research, v. 81, n. 2, p.

HARRÉ, Rom; MADDEN, Edward H. Causal powers. Oxford: Basil Blackwell, 1975.

JACOBI, Pedro. Educação e meio ambiente: transformando as práticas. Revista Brasileira de Educação Ambiental, Brasília, n. 0, p. 28-36, 2004.

JODELET, Denise. Representações sociais: um domínio em expansão. In: JODELET, Denise (Org.). As representações sociais. Rio de Janeiro: EDUERJ, 2001. p. 17-44.

JUBIEN, Michael. Contemporary metaphysics. Oxford: Blackwell Publishing, 1997.

LEFĖVRE, Fernando; LEFĖVRE, Ana Maria C. 0 discurso do sujeito coletivo: um novo enfoque em pesquisa qualitativa (desdobramentos). Caxias do Sul: EDUCS, 2003. (Coleção Diálogos).

Depoimentos e discursos: uma proposta de análise em pesquisa social. Brasília: Liberlivro, 2005. 
MOSCOVICI, Serge. Sociedade contra natureza. São Paulo: Editora Francisco Alves, 1985.

. Representações sociais: investigações em psicologia social. Petrópolis: Vozes, 2003.

REIGADA, Carolina; TOZONI-REIS, Marilia F. de Campos. Educação ambiental para crianças no ambiente urbano: uma proposta de pesquisa-ação. Ciência \& Educação, Bauru, v. 10, n. 2, p. 149-159, 2004.

ROSSET, Clément. A anti-natureza: elementos para uma filosofia trágica. Rio de Janeiro: Espaço e Tempo, 1989.

ROSSI, Paolo. 0 nascimento da ciência moderna na Europa. Bauru: EDUSC, 2001.

SANTOS, Milton. Técnica, espaço, tempo: globalização e meio técnico-científico-informacional. São Paulo: Hucitec, 1994.

SEGATO, Rita Laura. Formações de diversidade: nação e opções religiosas no contexto da globalização. In: ORO, Ari Pedro; STEIL, Carlos Alberto. Globalização e religião. Petrópolis: Vozes, 1999. p. 219-248.

TAVARES, Fernanda R. de Pinho. Educação ambiental na escola: a perspectiva estudantil sobre o meio ambiente e a propaganda ambiental na Internet. Ensaio: Pesquisa em Educação em Ciências, Belo Horizonte, v. 7, n. especial, p. 1-21, 2005.

TIPLER, Paul. Física. v. 1. Rio de Janeiro: Livros Técnicos e Científicos, 1991.

TOZONI-REIS, Marília F. de Campos. Formação dos educadores ambientais e paradigmas em transição. Ciência \& Educação, Bauru, v. 8, n. 1, p. 83-96, 2002.

VON ENGELHARDT, Dietrich. Science, society and culture in the Romantic Naturforschung around 1800. In: TEICH, Mikulas; PORTER, Roy; GUSTAFSSON, Bo (Eds.). Nature and society in historical context. Cambridge: Cambridge University Press, 1997.

Recebido em: 28.10.2011

Aprovado em: 20.08.2012

Carolina Lima Alves Belo é bióloga e mestre em Educação em Ciências e Saúde pelo Núcleo de Tecnologia Educacional para a Saúde da Universidade Federal do Rio de Janeiro (NUTES-UFRJ). E-mail: carolinabelo@yahoo.com.br.

Eliane Brígida Morais Falcão é doutora em Ciências pelo Instituto Alberto Luiz Coimbra de Pós-Graduação e Pesquisa de Engenharia da Universidade Federal do Rio de Janeiro (Coppe-UFRJ), pós-doutora pela Universidade de Cambridge (UK) e professora-associada do Núcleo de Tecnologia Educacional para a Saúde da Universidade Federal do Rio de Janeiro (NUTES-UFRJ).

Flavio Silva Faria é doutor em Biofísica pelo Instituto de Biofísica da Universidade Federal do Rio de Janeiro e professoradjunto no Instituto de Biologia da Universidade Federal do Rio de Janeiro (IB-UFRJ). E-mail: flavio@biologia.ufrj.br. 